\title{
On Reducing the Amplitude of Surface Waves by Source Arrays
}

\author{
G. C. Werth
}

\section{DISCLAIMER}

This report was prepared as an account of work sponsored by an agency of the United States Government. Neither the United States Government nor any agency thereof, nor any of their employees, makes any warranty, express or implied, or assumes any legal liability or responsibility for the accuracy, completeness, or usefulness of any information, apparatus, product, or process disclosed, or represents that its use would not infringe privately owned rights. Reference herein to any specific commercial product, process, or service by trade name, trademark, manufacturer, or otherwise does not necessarily constitute or imply its endorsement, recommendation, or favoring by the United States Government or any agency thereof. The views and opinions of authors expressed herein do not necessarily state or reflect those of the

RECEIVED

JAN 3019.97

OSTI United States Government or any agency thereof.

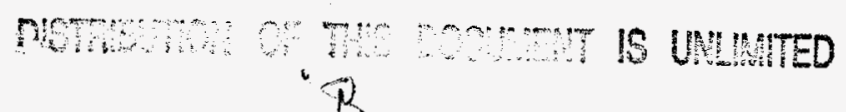

November 23, 1959

This is an informal report intended primarily for internal or limited external distribution. The opinions and conclusions stated are those of the author and may or may not be those of the Laboratory.

Work performed under the auspices of the U.S. Department of Energy by the Lawrence Livermore National Laboratory under Contract W-7405-ENG-48. 


\section{DISCLAIMER}

Portions of this document may be illegible in electronic image products. Images are produced from the best available original document. 
November 23, 1959

TO: Distribution

FROM: G. C. Werth

SUBJECT: Report "On Reducing the Amplitude of Surface Waves by Source Arrays".

The Geneva conference of experts stated that surface waves help define the nature of a seismic perturbation. A "phase equalization" method has been proposed by several seismologists to determine the polarity of the source using crustal surface waves. In this report a horizontal source array is designed which will reduce the amplitude if the crustal surface waves by a factor of five. Experimental data from Geophysical Prospecting is cited to support the effectiveness of such arrays. It is thought that phase shifts will accompany this amplitude reduction. It is concluded that these amplitude and phase changes will make the phase equalization method unreliable. The significance of the report is that the Geneva negotiations must take into account the possibility of horizontal as well as vertical arrays. The work is in an early stage of developement; criticism will be appreciated.

$$
\text { skene warth }
$$

Glenn C. Werth

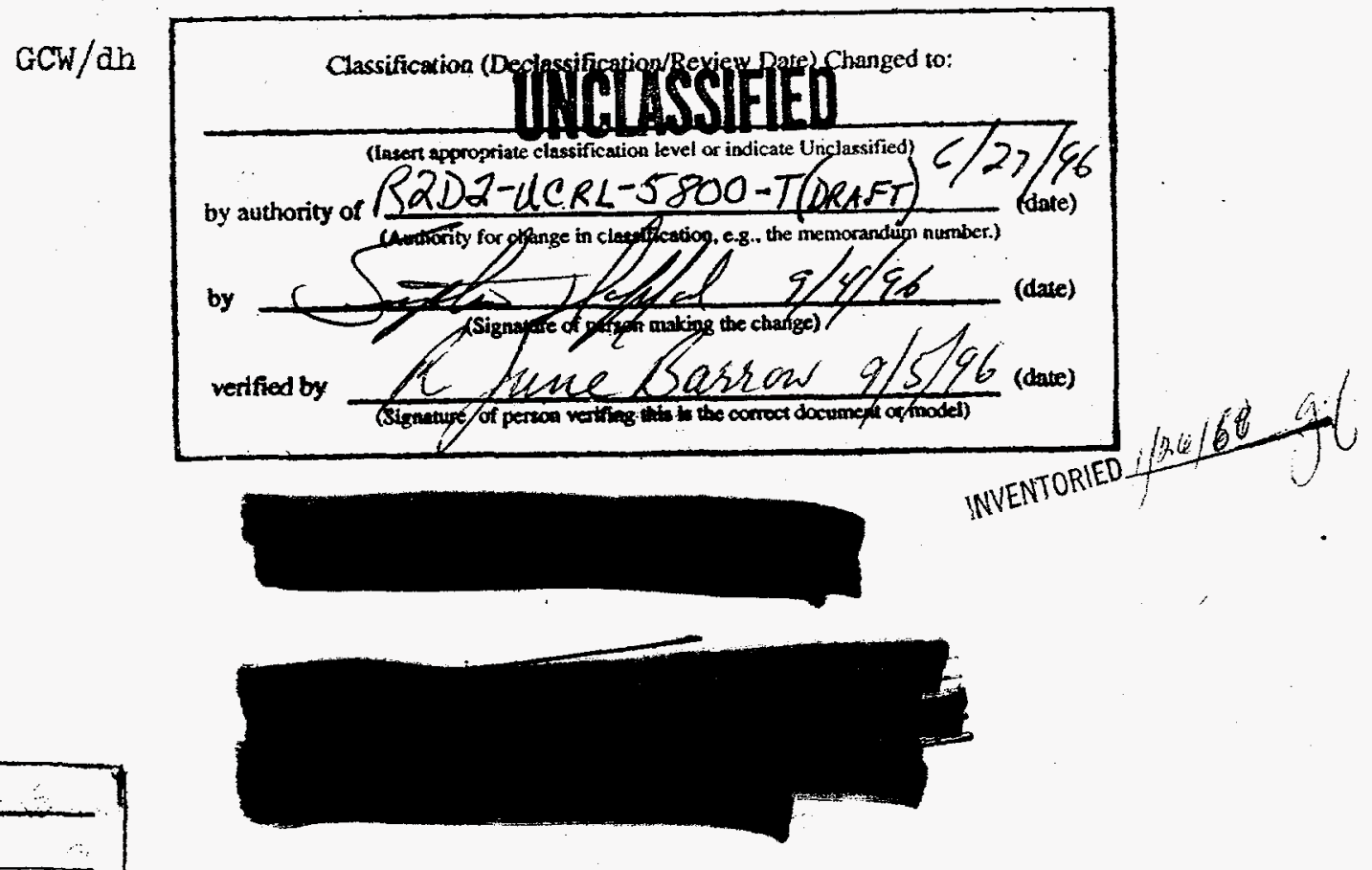


sources would have to be known. Such information can not be obtained from present interpretational techniques for epicenter location. We are forced to conclude that an can confuse the surface wave interpretation as easily as the longltudinal wave interpretation. These factors should be borme in mind in writing a treaty.

Oil Company Experience in The Design of Source Arrays

In "good" record areas surface waves are not a problem because either they are highly attenuated by the particular geologic formation or their frequencies are below the frequencies of interest and can be eliminated through flltering. In "poor" record areas, if surface waves are observed, It is routine for the prospecting crew to take steps to eliminate them. The velocity (phase) and dominent frequency is measured from the record. Standard charts are consulted to design either a recelver array or source array or both. If the area is such that topographlc irregularities reflect the surface waves back to the geophone line, a pattern or two dimensional source array is required. Otherwise a simple line array is sufficient.

The theoretical results of arrays with two through six units are sumarized In F1gs.I and 2. These graphs are taken from Parr and Mayne (1955) but they were first described for selsmic work in a patent by Taylor (1931). These curves glve the steady state response. Transient analyses bave also been made but it is found that the transient results are not very alfferent from an "eyeball" average through the loops and nodes of the reject region. since crustal surface waves at Geneva Network distances should be fairly well dispersed, the steady state response is the one that should be used when working with amplitude discrimination.

As expected, the curves show that as the number of elements is increased, the band width of the rejected waves becomes larger and there is more rejection. Various authors claim that an adiltion rejection, by a factor of two or so can be obtained by departing from the uniform strength of individual units to particular variable strengths.

Experimental work has proven that these design criteria are effective. Flgure 3 is reproduced from Parr. The lower panel clearly shows a surface wave

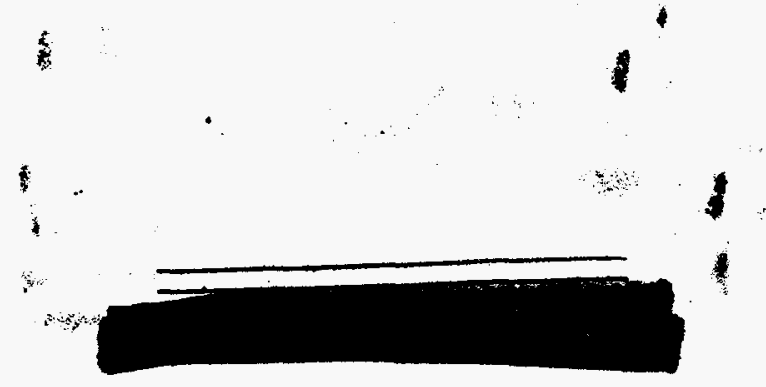


of high amplitude generated by a single charge extending from 4.5 seconds on the bottom trace to 8 seconds on the top trace. The upper panel using an array shows no evidence of this surface wave. Instead the automatic gain control has raised the Gain sufficiently to see good reflections at the surface wave time. The fifteen element array in Fig. 3 is equivalent to a 6 or 7 element line array in any particular direction.

Figure 4 gives a second experimental verification of the effectiveness of arrays in $d_{i}$ scriminating against surface waves. The illustration is from an article by Domenico (1958). In this instance the seismic energy is generated by dropping a three ton weight nine feet onto the ground. The receiver set up Is maintained constant and the drop truck has proceeded from 2,000 feet to 4,000 feet dropping the weight at 20.8 foot intervals.

The upper panel clearly shows a well developed surface wave. A four element line source array is simulated by suming four adjacent traces. The surface wave has been almost eliminated. We maintain that this four trace summation is essentially identical to the record that would have been obtained if four weight dropping trucks were used simultaneously.

Although these experiments were not designed to obtain a precise quantitative measure, a prospecting seismologist readily accepts them as proof that the factors of reauction of five or so predicted by theory are found in practice. Design of a Test Facility To Reduce Surface Waves

The array will be designed to discriminate against cristal surface waves. The highest amplitude part of the wave, the Airy phase, occurs at the group velocity minimum. Experimentally the minimum occurs at a period 18 seconds. A representative phase velocity for this period is $3.4 \mathrm{~km} . / \mathrm{sec}$. (see Fig. 5) (Ewing and Press (1959)). We ehoose a 4 element array with dimensions such that $\lambda / \mathrm{D}=2.4$ with $\lambda=(3.4)(18)=61 \mathrm{~km}$. Hence $\mathrm{D}=25.4 \mathrm{~km}$. in the direction of a particular network station. Two layouts of a clandestine test facility designed to discriminate against surface waves are shown in Fig. 6. By geometry successive elements for the line array are $34.2 \mathrm{~km}$. apart.

We now calculate the reject band width. According to Fig. 1, the band width runs from $\lambda / D=1.3$ to 5.1 or $\lambda=33$ to 130 . The periods are $\mathrm{T}=33 / 3.25=10.1 \mathrm{sec}$. to $\mathrm{T}=130 / 3.8=35.8 \mathrm{sec}$. The phase velocities have $\cdot$

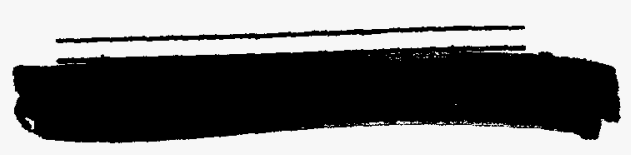


been taken from Fig. 5. Most of the crustal wave energy is contained within this frequency band.

The reduction in this band averages .2 or a facor of 5 . Details can be examined in Fig. 1. Although no experimental date on surface waves from nuclear detonations are available at IRL, we conjecture that more energy is put into the wave by the source at periods below the Airy frequency than above. If this is true then the higher amplitude parts of the surface wave would be reduced by a factor approaching ten. Further reductions are possible (facter of 2 or so) by having different strengths in the individual members of the array. Of course with more elements in the array, more reduction over a wider band can be obtained.

Although detailed calculations have not been made it would appear that, because of the rarefaction first motions, and the large epicenter location uncertainty by S-P methods, a seismologist might prefer an earthquake-in-. the-mantle interpretation. (See the report by Werth (1959)).

Theoretical calculations on the waveforms of surface waves are not far enough along at LRL to show what would happen if the Brune Oliver-Aki source function technique were used. We make the following speculation. Flrst of all the amplitude would be down by a factor of 5 . However, careful flltering may still reveal a remant surface wave. The Brune Oliver-Akl technique assumes a single impulse type source (no phase shifts at the source) at a known distance. There is too much uncertainty in the distance to apply it here. If a particular aistance were chosen, and even if it were correct.for one of the sourees, it is expected that the effect of the nultisources is to introduce drastic phase shifts in an assumed equivelent single source function. It. might be possible to design this array to give earthquake type polarities for surface waves. In order to be silre of these statements, we will have to walt until theoretical waveforms fror multisources are derlved for various configurations. The amplitude reduction can be depended upon because of the oil company experience.

The discussion so far has been based on the first ring of network stations. Oil company work shows that three to four additional elements are necessary to obtain the same reduction independent of direction.

There is no intent to minimize the contribution of the Brune Oliver-AkI technique to the general scientific literature, only to point out that complications arise in applying the technique to the Geneva system if arrays are used.

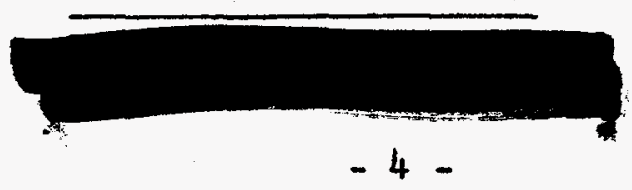




\section{Significance}

While crustal surface waves may be of some help in the detection and identification of underground nuclear detonations, it should be bome in mind that they can be materially changed in amplitude and probably phase as well by using an array. Any rules ior on-site inspection must recognize the possibility of horizontal as well as vertical arrays. Extreme care must be taken not to over simplify the technical situation in the wording of a treaty.

\section{DISTRIBUTION :}

Adams, $W$.

Adiemann, $F$.

Bing, G.

Brown, H.

Fernbach, $s$.

Futterman, W.

Heckrote, $W$.

Herbst, R.

Johnson, G.

Latter, A.

Leith, $\mathrm{C}$.

Nucholls, J.

Oliver, J.

Press, F.

Rormey, C.

Scharff, M.

Short, N.

Werth, G.

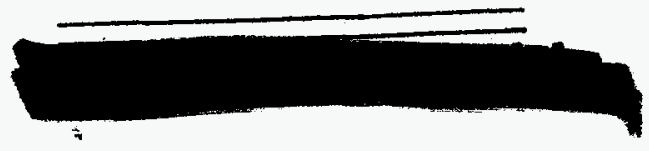


Aki, Keiiti, (1959), Study of Rarthquake Mechanism by a Method of Phase Equalization Applied to Rayleigh and Love Waves, to be published.

Domenico, S. N. (1958), Generation of Seismic Waves by Weight Drops, Geophysics, Vol. 23, No. 4, P. 665-83.

Ewing, M., Press, F., Determination of Crustal Structure From Phase Velocity of Rayleigh Waves, Bull. Geologic Society of America, Vol. 70, No. 3, P. 229-244.

Parr Jr., J. O., Mayne, W. E. (1955), A New Method of Pattern Shooting, Geophysics, Vol. 20, No. 3, P. 539-64.

Taylor, H. G. (1931), Method of Recording Selsmic Waves, U. S. Patent 1799398.

Tukey, J., (1959), Equalization and Pulse Shaping Techniques Applied to the Determination of Initial Sense of Rayleigh Waves, Appendix 9 in The Need for fundamental research in seismology, Department of State.

Werth, G. C. (1959), The Simulation of Certain Selsmic Effects of Earthquakes With Nuclear Detonations, Lawrence Radiation Laboratory Report UCRL 5712-T.

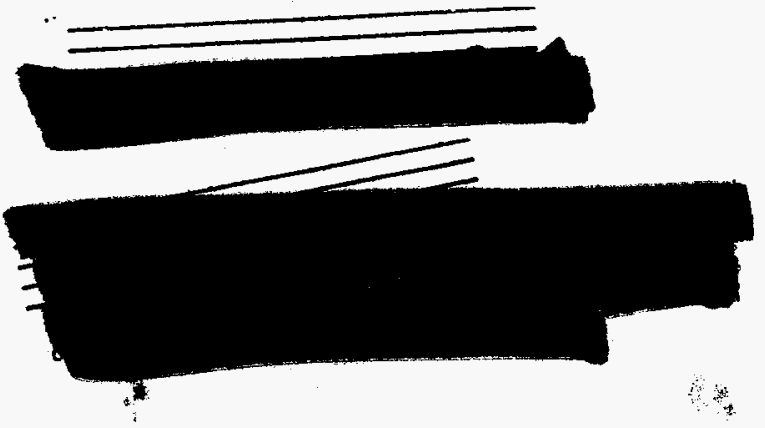




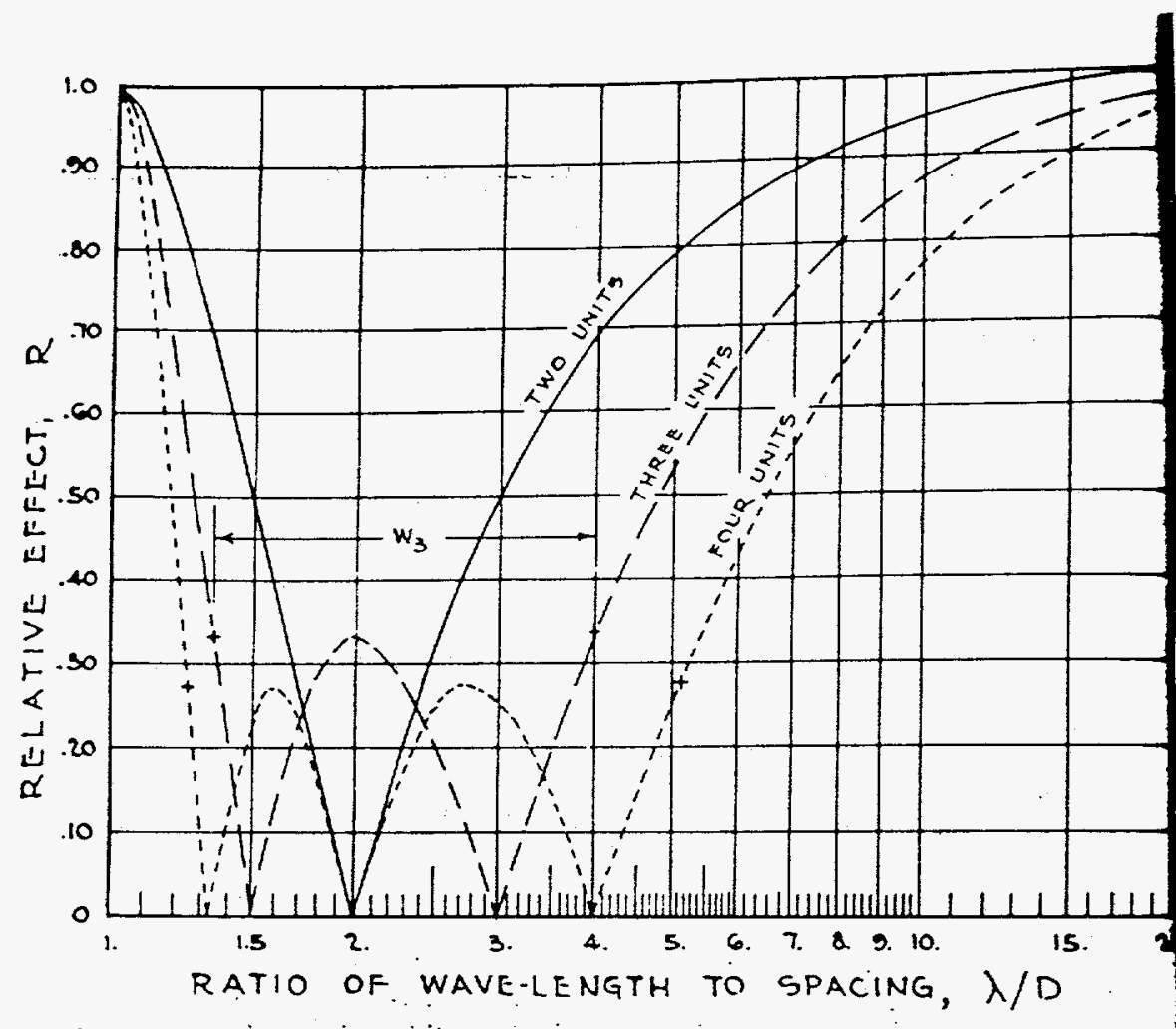

The relative effect, $R$, of uniformly effective units with a uniform spracing in line as - function of $\lambda, D, \lambda$ is the wavelength if the reccived energy. $D$ is the spacing hetween the units, and $R$ is the ratio of the relative effect of the spaced units w what it would le if all units were bunched at the center of the group. The sold line shows the relative eflect of two unils (detectors or charges) The dashed line shows the relative effect of three uniformly effeclive urits. The dotted line shows the relative effect of four uniform! etreetise uniss.

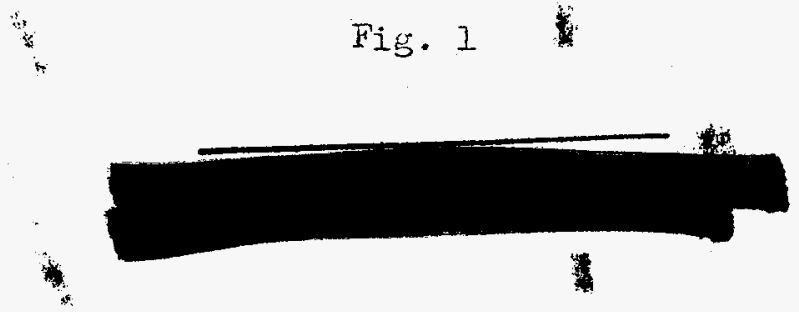




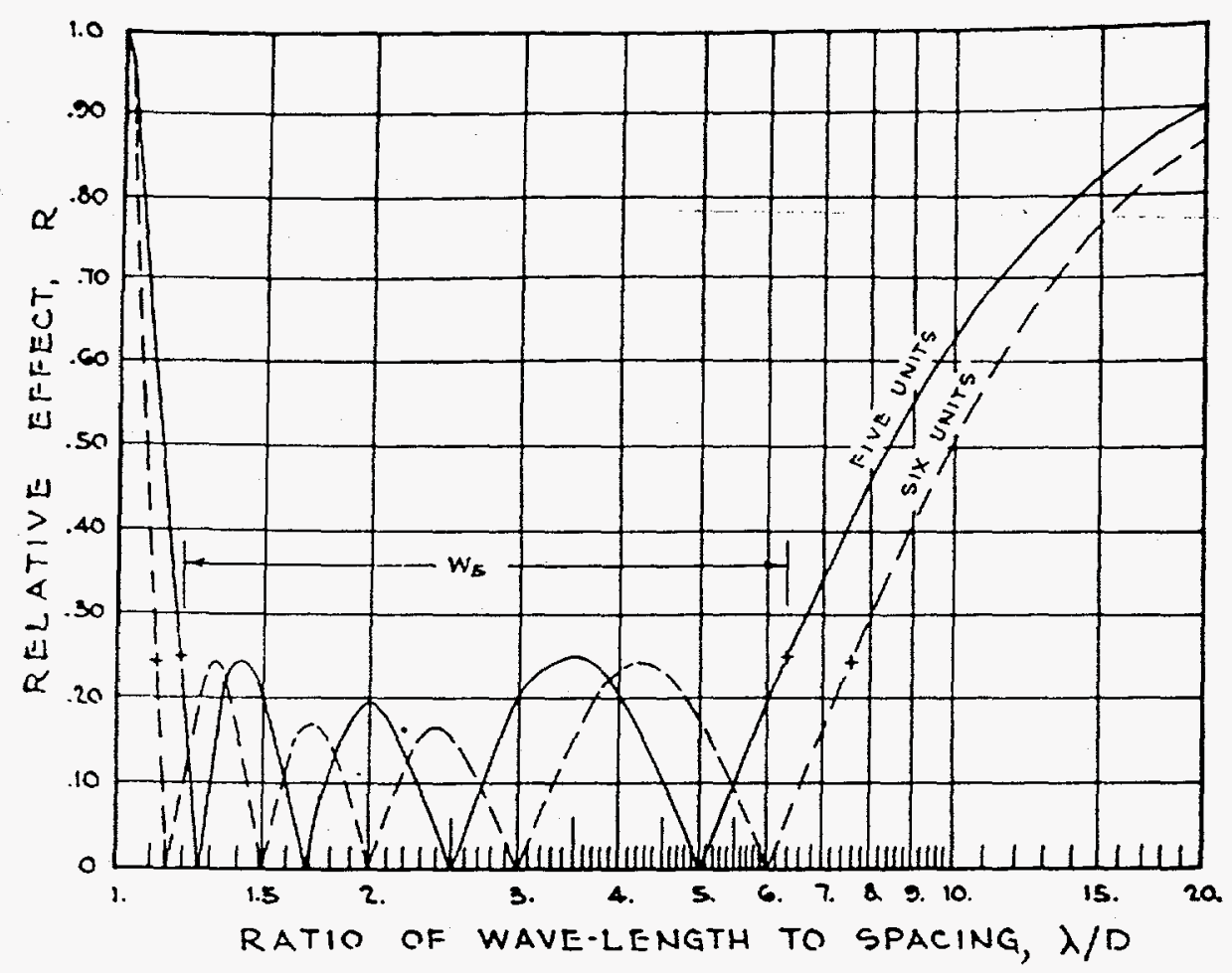

Same as Figure i except that the solid line represents the relative effect of five uniformly elfective units and the dashed line shows the relative effect of six uniformly effective units.

FiE. 2

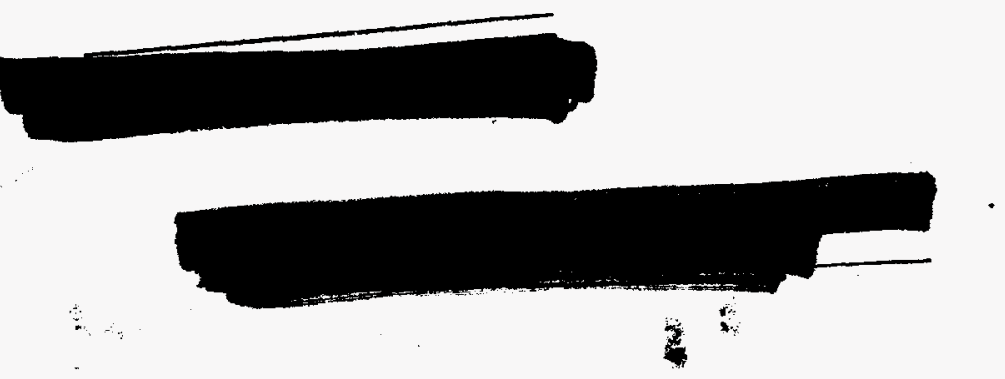



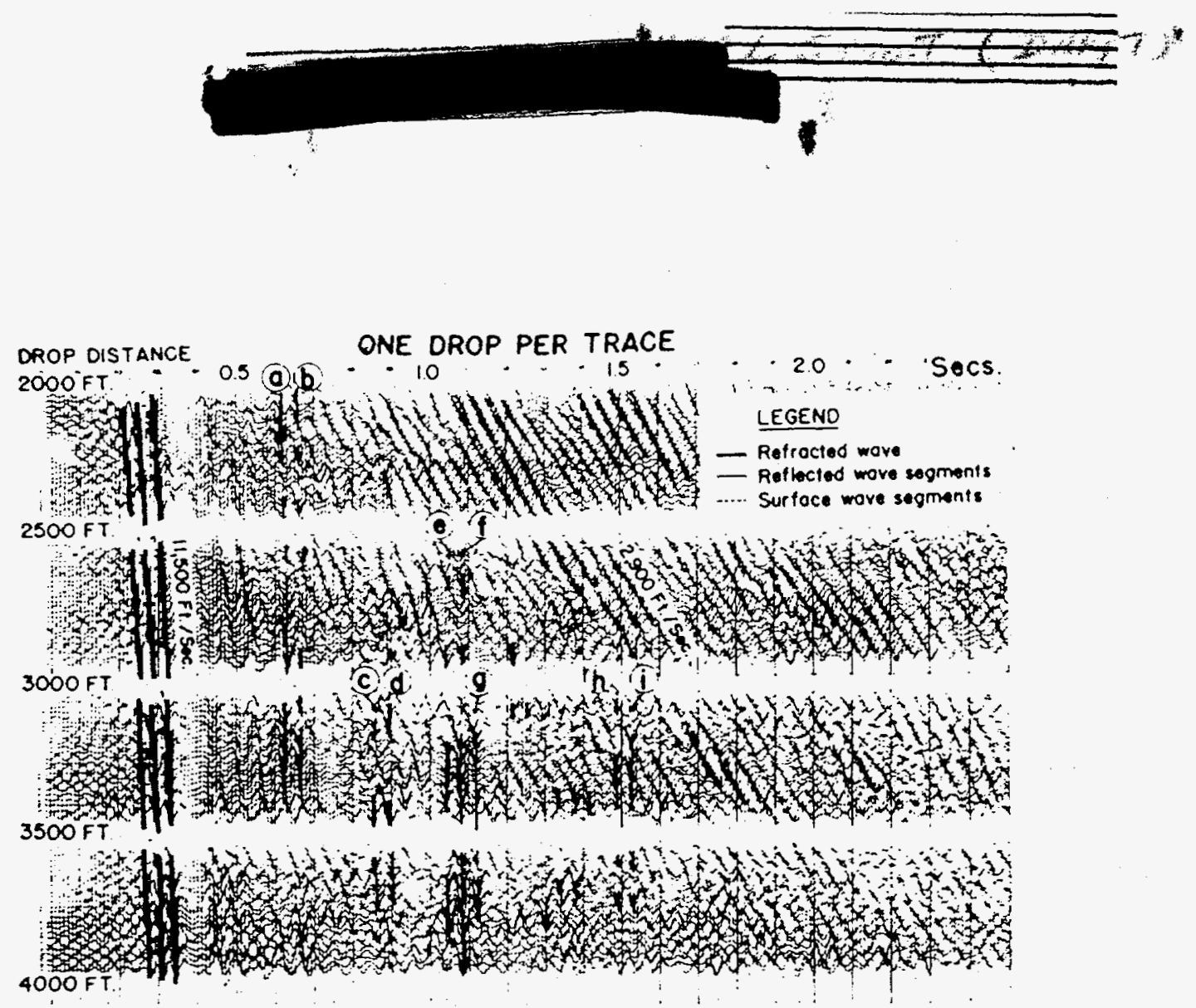

FOUR DROPS PER TRACE (DROP COMPOSITE $4 \%$ )

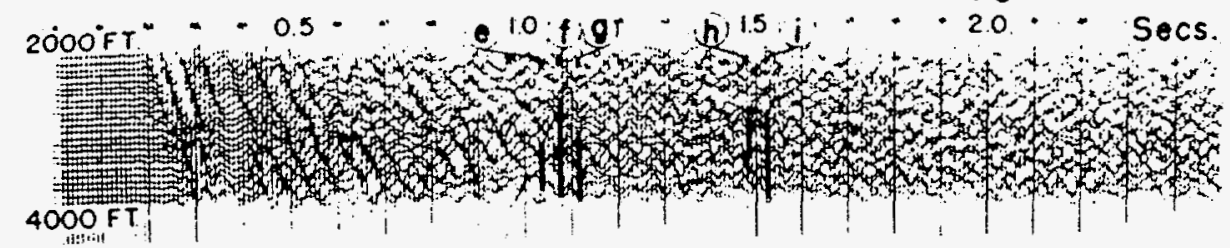

24 DROPS PER TRACE (DROP COMPOSITE $24 / 12$ )

$2000^{\circ} \mathrm{FT}=05: \cdots 10190 \%$ Secs. 400̈न

Records from Test site 11. Tritces on the upper four records represent single dirops at 20.8-it intervals along a line extending $2,(\mathrm{~K})$ (o) 4,000 if irom the recording scismometer station containing 36 seismometers. The fotton iwn records were obtained hy compositing these drof inur to a trace and 24 to a trace. respectively:

FiE. 4

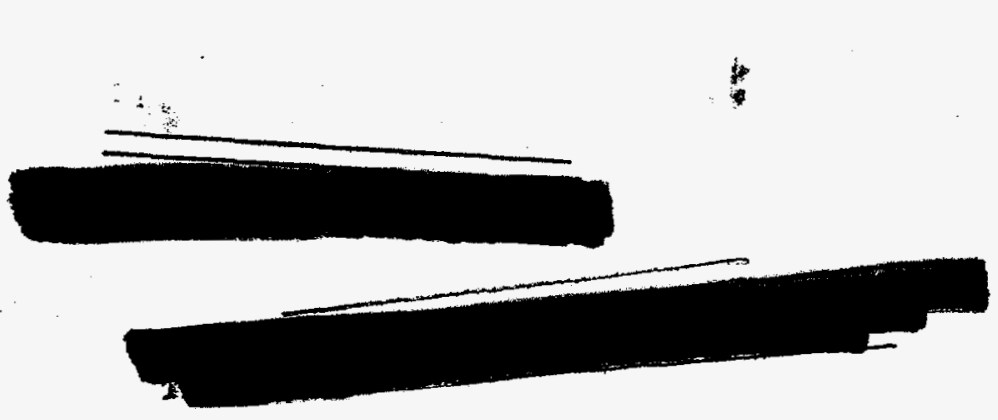


$\because$

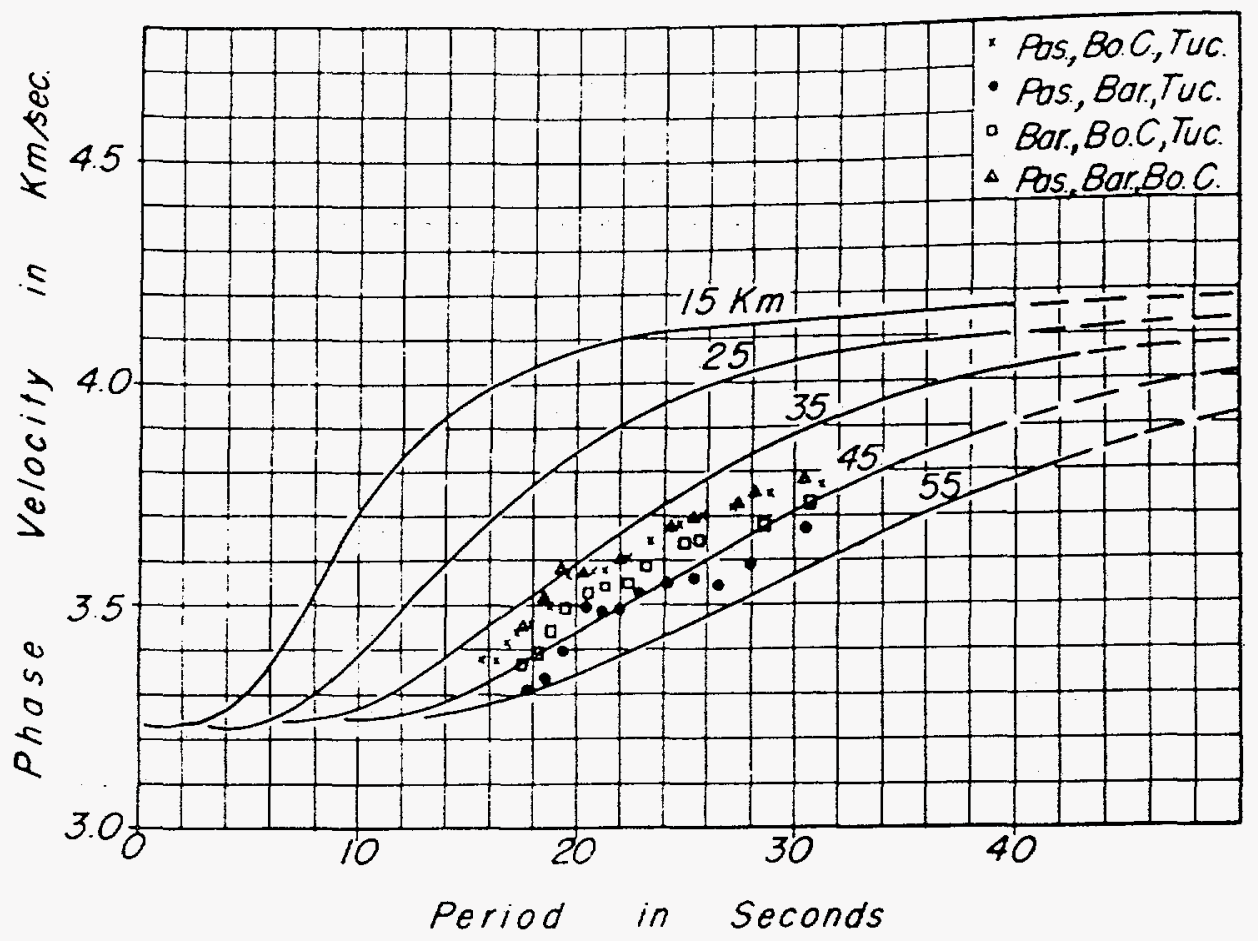

-Phase-Velocity ljterminatrons for Peningtlar Ranges-Southuest Desert Region

FiẼ 5

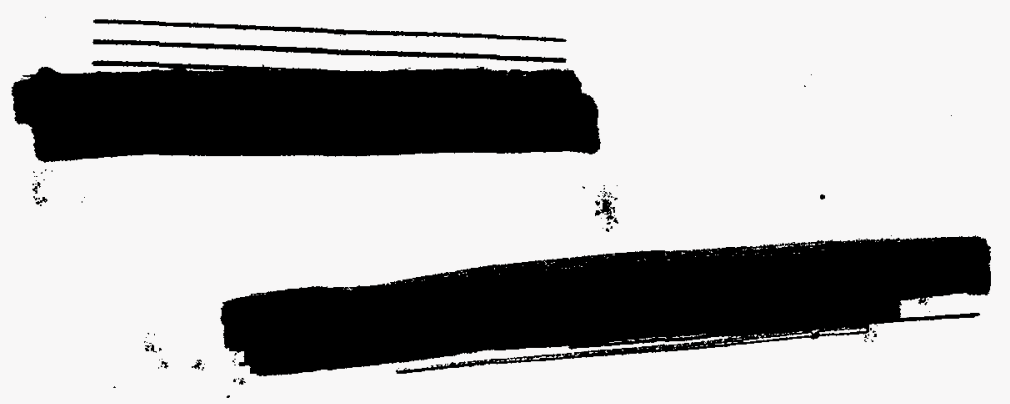


... Network

Station

First $\Delta$

Motion

Compression network

$\rightarrow$ Station

$\triangle$ First Motion

Compression

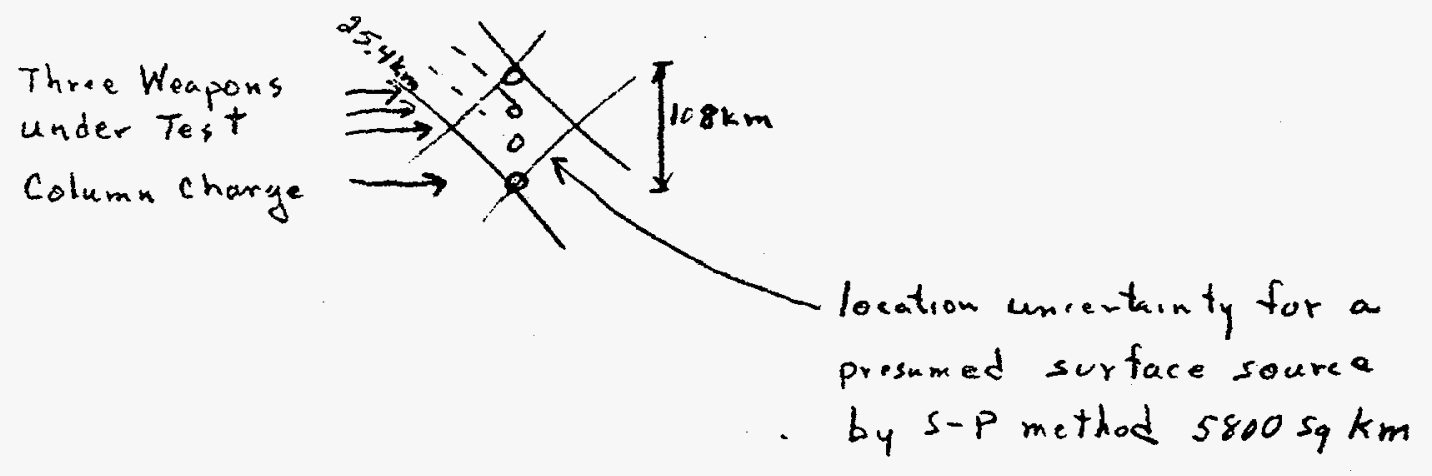

Network

Station $\Delta$

First Motion

rarefaction
Network

$\triangle$ Station

First Motion

rarefaction

Linear Array To Reduce The Amplitude of Crustal Surface Waves

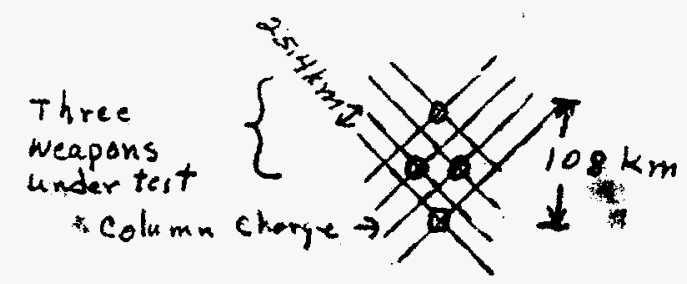

Alternate Source Arrangement equally effective

Fond 6

Worth $11 / 23 / 59$ 